\title{
Luminescence Based Detection of Trinitrophenol and Aromatic Organophosphorous Pesticides Using a Coordination Polymer
}

\author{
Rupinder Kaur, ${ }^{1}$ Manmohan Chhibber, ${ }^{1}$ Partha Mahata ${ }^{2}$ and Susheel K. Mittal ${ }^{* 1}$ \\ ${ }^{1}$ School of Chemistry \& Biochemistry, Thapar University, Patiala-147004, India. Email: smittal@thapar.edu \\ 2 Department of Chemistry, Jadavpur University, Kolkata-700 032, India Email: parthachem@gmail.com
}

Received February $3^{\text {rd }}, 2017$; Accepted September $18^{\text {th }}, 2017$

\begin{abstract}
The fluorescent properties of a coordination polymer (CP), 1, were used as turn-on and turn-off detector for nitroaromatics and organophosporus pesticides respectively. Compound $\mathbf{1}$ exhibits exceptionally high efficiency for the detection of 2,4,6-trinitrophenol (TNP) through luminescence quenching with a quenching constant $\left[\mathrm{K}_{\mathrm{SV}}\right]$ value of $2.30 \times 10^{5} \mathrm{M}^{-1}$, highest among the known coordination polymers. Minimum detection limit achieved by the proposed method was $43 \mathrm{ppb}$. This emission property of $\mathbf{1}$ was also used successfully to detect triazophos and chlorpyrifos, aromatic organophosphorus pesticides, which enhanced the emission intensity by $238 \%$ and a red shift of $\sim 70 \mathrm{~nm}$ in case of former. Non aromatic pesticides like malathion and acephate did not show any increase in the emission intensity. Minimum detection limits for triazophos and chlorpyrifos, aromatic organophosphorus pesticides, were 0.6 and 0.7 ppm respectively.
\end{abstract}

Key words: nitro-explosives; TNT; acetylcholinesterases; acetylcholine; molecular sensing; MOF

\section{Introduction}

Being highly porous and crystalline, coordination polymers (CPs) belong to a better class of solids in comparison to the zeolites. Owing to the fact of unmatched structural diversity, tunability and the possibility of post synthetic modification which generally lacks in zeolites, coordination polymers have been explored extensively during the last decade. Recently, CPs are being explored for their potential applications such as heterogenous catalysis,[1] gas storage,[2-3] drug delivery,[4-5] and molecular sensing [6-9]. These macromolecules can efficiently behave as receptor and equally good signal transducer due to their porous nature coupled along with luminescence properties, the foremost requirement to be developed into a good sensor.

The property of luminescence in CPs has become an active area of research due to its potential applications [10]. This is evident from geometrical hike in the number of reports during the last few years related to the sensing of nitroaromatics, the active components or by-products of explosives, [11-16] and important issues related to homeland security and environment. TNP is a key energetic ingredient for the preparation of landmines and improvised explosive devices. [17] It
Resumen: Las propiedades fluorescentes del polímero de coordinación (CP), 1, fueron utilizadas como detectores de encendido y apagado, para pesticidas nitroaromáticos y organofosforados, respectivamente. El compuesto 1 muestra una eficiencia extraordinariamente alta para la detección del 2,4,6-trinitrofenol (TNP) utilizando la atenuación de la luminiscencia, con un valor de la constante de atenuación $\left[\mathrm{K}_{\mathrm{SV}}\right]$ de 2.30 X $10^{5} \mathrm{M}^{-1}$, la más alta entre los polímeros de coordinación conocidos. El límite de detección obtenido para el método propuesto fue de 43 ppb. La propiedad de emisión del compuesto 1 fue también utilizada exitósamente para detectar el triazofos y cloropirifos, pesticidas órganofosforados aromáticos, los cuales incrementan la intensidad de emisión en un $238 \%$ y un desplazamiento hacia el rojo de $\sim 70 \mathrm{~nm}$, para el primer compuesto. Los pesticidas no aromáticos como el malatión y el acefato no mostraron un incremento en la intensidad de emisión. Los límites de detección para triazofos y cloropirifos, pesticidas órgano osforados aromáticos, fueron de 0.6 and $0.7 \mathrm{ppm}$, respectivamente.

Palabras clave: nitro-explosivos; TNT; acetilcolinesterasas; acetilcolina; detección molecular; MOF

has been reported that TNP is a much stronger explosive than 2,4,6-trinitro toluene commonly known as TNT[18]. Beside explosives, TNP is also used in glass, match sticks, fireworks, dyes and in leather industry. [17, 19-20] TNP is also known to cause obnoxious effects on human heath such as irritation to skin, eyes and damage to the respiratory system. [21] Therefore, development of detection methodologies for TNP is of immense significance for the safety and security of life.

Aromatic organophosphate pesticides are another class of chemicals with a threat to the environment due to accumulation in soil after use and their transfer to food chain via water, grains, milk and poultry products. Chlorpyrifos and triazophos are two widely used aromatic organo phosphorous pesticides in many countries that have adverse effects on human health. Their toxic nature can be realized from their ability to inhibit acetylcholinesterases (AChE), an enzyme that causes rapid hydrolysis of a neurotransmitter acetylcholine, thus preventing nerve impulses in human body causing neurological problems [22]. Thus, there is a need to detect these compounds accurately and efficiently even in trace amounts.

Current methods to detect explosives include trained canines or sophisticated instruments, [23] such as ion mobility 
spectrometry, [24] energy dispersive X-ray diffraction, [25] plasma desorption mass spectrometry, [26] surface-enhanced Raman spectroscopy [27-29] and different imaging technologies. [30] For pesticide detection commonly used techniques are gas chromatography, [31-32] high performance liquid chromatography [33-34] and mass spectrometry. [35] Although these established methods are highly sensitive and accurate they suffer from a number of disadvantages such as high cost of instruments, complex functioning and lack of portability. The use of luminescence property of CPs for the detection of hazardous chemicals seems a logical alternate. [36] Recently, Kumar et al have reported two different CPs having $\mathrm{Zn}$ and $\mathrm{Cd}$ as metal centres to behave as sensitive detectors for nitro containing organophoshate pesticides. [37-38]

Considering above advantages, we have used a two-dimensional Co-based $\mathrm{CP}, \quad\left[\mathrm{Co}(\mathrm{OBA})\left(\mathrm{H}_{2} \mathrm{O}\right)_{2}\right] \quad[(\mathrm{OBA}=$ 4,4'-oxybis(benzoate)], 1, prepared using an earlier reported protocol,[39] for the sensing of nitro explosives and pesticides. We found that all the nitroaromatics behave as fluorescence quenchers for CP,1, with TNP being the most efficient and nitrobenzene being the least quencher. Organophoshate pesticides namely triazophos and chlorpyrifos, on the other hand, exhibited a turn-on luminescence behaviour. This is the first observation, to the best of our knowledge, where same CP has been used for the detection of nitro-explosives and aromatic organophosphate pesticides simultaneously through two different luminescence behaviours (turn-on and turn-off). In this article, we present the detailed studies of luminescence based detection behaviour of $\mathbf{1}$ for nitroaromatics and pesticides.

\section{Results and Discussion}

\section{Synthesis, Characterization and Structure of CP}

The coordination polymer, $\left[\mathrm{Co}(\mathrm{OBA})\left(\mathrm{H}_{2} \mathrm{O}\right)_{2}\right] \quad[\mathrm{OBA}=$ 4,4'-oxybis(benzoate)], 1 was synthesized using a convenient solvent evaporation method taking $\mathrm{CoCl}_{2} \cdot 6 \mathrm{H}_{2} \mathrm{O}$ and $4,4^{\prime}$-oxybis (benzoic acid) as precursors and water as a solvent. The crystal structure of as-synthesized CP was characterized with the help of powder X-Ray diffraction technique (P-XRD) (Fig. $\mathrm{S} 1)$. The diffraction pattern of the Co-MOF was found to be in complete agreement with the simulated pattern generated from the single crystal data and with that of the earlier reported literature.[39] The pattern shows two sharp and major peaks at $2 \theta=6.97^{\circ}, 13.8^{\circ}$ suggesting its highly crystalline nature and a multiplet ranging from $18.1^{\circ}-21^{\circ}$. Briefly, the structure of $\mathrm{CP}, \mathbf{1}$, consists of $\mathrm{Co}^{2+}$ ions connected by the oxybis(benzoate) units forming a two-dimensional layered structure where inter-layer hydrogen bond interactions gives rise to supra-molecularly organized three-dimensional structure as shown in fig. 1 .

\section{Nitroaromatic sensing}

Compound 1 when dispersed in water exhibited a violet emission centred at $411 \mathrm{~nm}$ upon excitation at $255 \mathrm{~nm}$. The observed emission is due to the intra-ligand transitions $\left(\mathrm{\Omega}^{*} \rightarrow \mathrm{n}\right.$ and $\mathrm{\Omega}^{*} \rightarrow$ л) of OBA ligands. Potential of $\mathbf{1}$ to detect trace amount of nitroaromatics was explored by incremental addition of analytes to its dispersed solution in water.

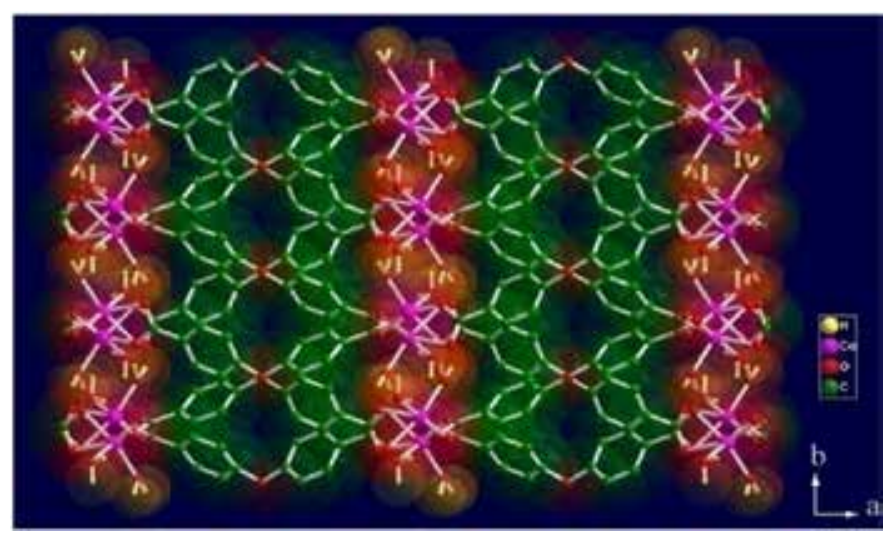

Fig.1: Two-dimensional layered structure where inter-layer hydrogen bond interactions for $\mathrm{CP}, 1$.

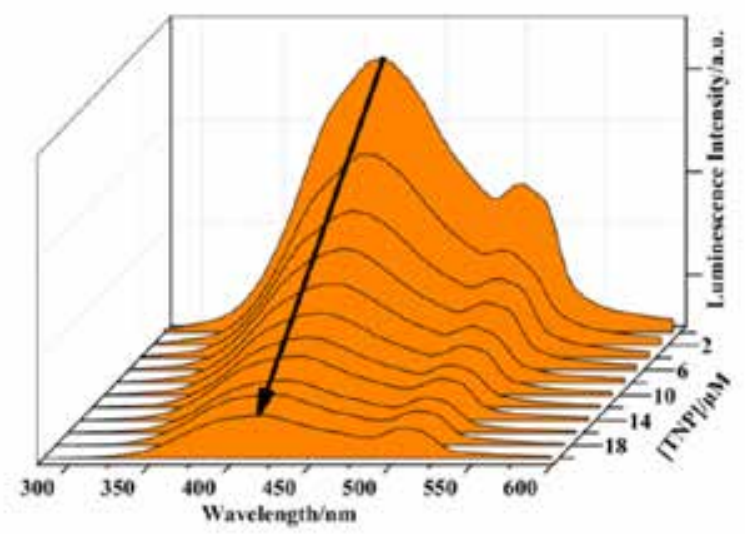

Fig. 2: Emission spectra of 1 dispersed in water upon incremental addition of 2,4,6-trinitrophenol solution $\left(\mathrm{I}_{\mathrm{ex}}=255 \mathrm{~nm}\right)$.

Fig. 2 shows gradual attenuation in luminescence intensity of 1 with incremental addition of TNP. A final addition up to 20 $\mu \mathrm{M}$ of TNP quenches the emission intensity of $\mathbf{1}$ to $84.5 \%$ of its initial intensity. Fig. 3 shows luminescence attenuation as low as $0.19 \mu \mathrm{M}$ which is equivalent to $43 \mathrm{ppb}$. These results clearly mark $\mathbf{1}$ as one of highly sensitive detectors.

Low detection limit of TNP encouraged us to perform similar luminescence quenching titrations with other nitroaromatics such as nitrobenzene, 4-nitrophenol, 4-nitrobenzoic acid, 1, 3-dinitro benzene, 2,6-dinitro toluene, benzene and toluene (ESI, Fig. S2-S8). The quenching efficiency (\%) was estimated using formula $\left(I_{0}-I\right) / I_{o} \times 100$, where $I_{o}$ is the fluorescence intensity without the addition of analyte and I being the intensity after the addition of analyte. Fig. 4 shows the quenching efficiency of all the analytes at $20 \mu \mathrm{M}$ concentration. Quenching efficiency of $84.5 \%$ with TNP is highest for $\mathbf{1}$ as compared to other nitroaromatics, thus proving sensitivity for its detection. Amongst others, the decreasing order of quenching efficiency 
was 2,6-dinitrotoluene (31.2\%), 1,3-dinitrobenzene (18.8\%), 4-nitrobenzoic acid (12.6\%), 4-nitrophenol (8.15\%) and nitrobenzene (2\%). Benzene and toluene, aromatic compounds without nitro groups, did not show any quenching behaviour.

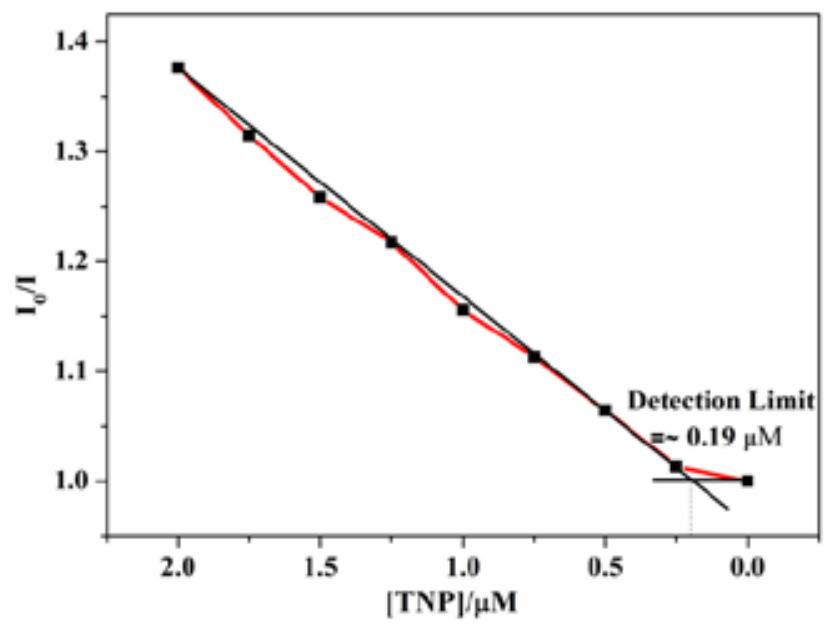

Fig. 3: Luminescence quenching $v s$. concentration of TNP plot indicating the detection limit (where $\mathrm{I}_{\mathrm{o}}$ is the luminescence intensity in absence of analyte and I is the luminescence intensity with incremental addition of TNP).

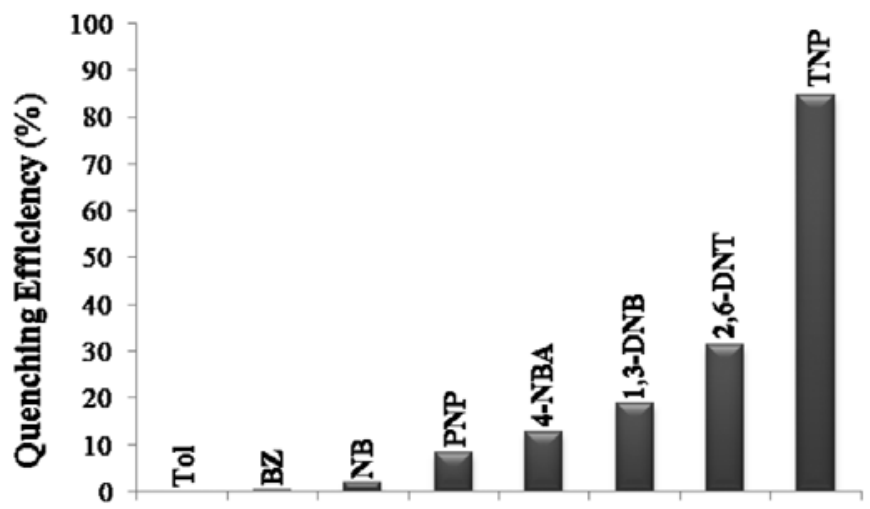

Fig. 4: Percentage luminescence quenching at $411 \mathrm{~nm}$ of 1 with $20 \mu \mathrm{M}$ of 2,4,6-trinitrophenol (TNP), 2,6-dinitrotoluene (2,6-DNT), 1,3-dinitrobenzene (1,3-DNB), 4-nitrobenzoic acid (4-NBA), p-nitrophenol (PNP), nitrobenzene (NB), benzene (BZ) and toluene (Tol).

The luminescence quenching efficiency of TNP was analyzed by fitting the experimental data to the Stern-Volmer (SV) equation, $\left(\mathrm{I}_{\mathrm{o}} / \mathrm{I}\right)=\mathrm{K}_{\mathrm{SV}}[\mathrm{A}]+1$, where $\mathrm{I}_{\mathrm{o}}$ and $\mathrm{I}$ are the luminescence intensities before and after the addition of analytes respectively, $[\mathrm{A}]$ is the molar concentration of the analyte and $\mathrm{K}_{\mathrm{SV}}$ is the quenching constant. As shown in fig. 5, at low concentration (upto $10 \mu \mathrm{M}$ ) of TNP a linear increase in $\left(\mathrm{I}_{0} / \mathrm{I}\right)$ 1 was observed. With the increase in concentration SV plot diverged from linearity and began to bend upwards in the case of TNP (see ESI, Fig. S9). The linear variation at lower concentration are mainly due to static quenching, whereas the steep curves at higher concentration are presumably due to dynamic quenching. The static quenching can be accredited due to the ground state interaction between the analytes and the compound $\mathbf{1}$. The dynamic quenching is mainly due to the energy and electron transfer processes between the analytes and the compound 1. Apart from these mechanisms, absorption of excitation light by the analyte itself may also contribute to the quenching effect. Fitting of the linear parts of the plots allow the determination of the quenching coefficients, $\left(\mathrm{K}_{\mathrm{SV}}\right)$ to be $2.30 \times 10^{5} \mathrm{M}^{-1}$. The larger observed $\mathrm{K}_{\mathrm{SV}}$ values correlate to extremely high sensitive systems indicating that $\mathbf{1}$ is one of the best reported luminescence probe to be used for the detection of TNP.

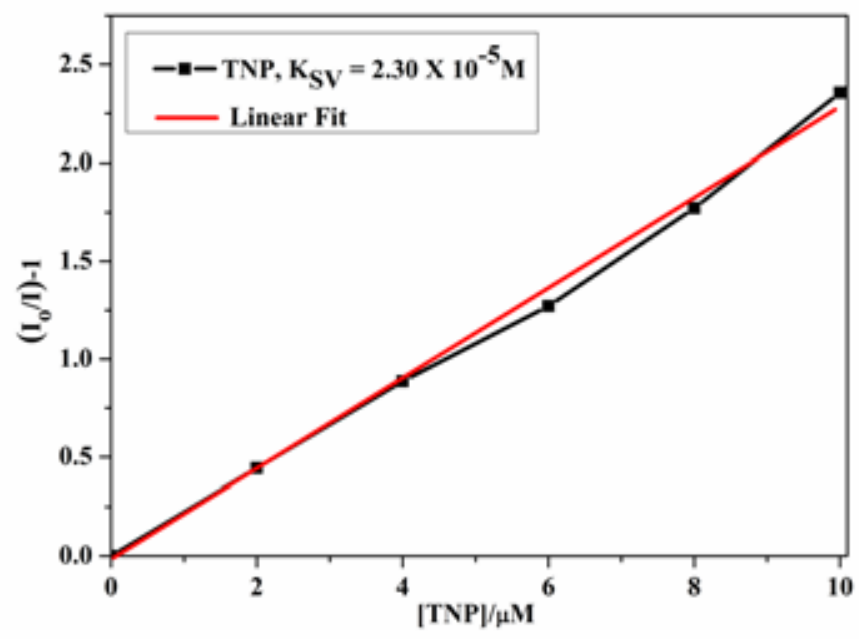

Fig.5: Stern-Volmer plot of $\mathrm{I}_{\mathrm{o}} / \mathrm{I}-1$ (at $411 \mathrm{~nm}$ ) vs. concentration of TNP (upto $10 \mu \mathrm{M}$ ). Io and I are the luminescence intensities in the absence and presence of TNP.

The homogeneous dispersible nature of the $\mathrm{CP}$ has enabled a close contact between 1 and the analytes. This enables proximity and molecular interaction between $\mathbf{1}$ and analytes leading to a significant amount of static quenching. Apart from static quenching, the mechanism of the luminescence quenching of 1 in presence of analytes is primarily due to the reduction of amount of excitation energy required to excite the ligands. The excitation energy losses are attributed to the two possible mechanisms: (i) Absorption of the excitation energy by the analytes by competing with the OBA ligand, and (ii) Part of excitation energy used for the transfer of electron from the excited state of the ligand to the LUMO of the analytes.

\section{Pesticide Detection}

"Turn-on" luminescence is another phenomenon which is used for the detection of various moieties these days. Turn-on phenomenon refers to evolution of a new peak from a blank background or increase of emission peaks usually in the visible region. The selective binding of an analyte molecule induces 
strong emission of generally low emitting host. Present work describes detection of organophosphorous pesticides using turn-on effect of $\mathbf{1}$. Incremental addition of organophosphorous pesticides namely, triazophos, chlorpyrifos, malathion and acephate (Fig. 6), was done to $\mathbf{1}$ in order to observe the effect on its luminescence. Interestingly, only aromatic organophosporous pesticides, triazophos and chlorpyrifos, induce the turn on phenomena in $\mathbf{1}$ among the selected analytes.

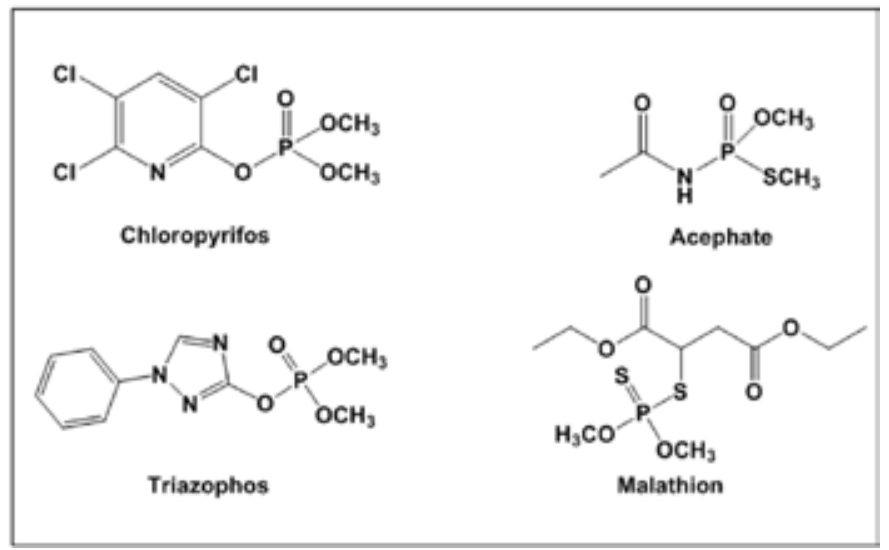

Fig. 6: Chemical structures of the aromatic organophosphorous pesticides (chloropyrifos and triazophos) and non-aromatic organophosphorous pesticides (acephate and malathion).

Triazophos turns on the luminescence, in $\mathbf{1}$, with a $\sim 70 \mathrm{~nm}$ red shifting of the emission peak (Fig. 7) while chlorpyrifos shows luminescence turn-on without shifting of the emission peak (ESI, Fig. S10). The original intensity of $\mathbf{1}$ was increased by $238 \%$ of its initial value in case of triazophos and by $29 \%$ in case chlorpyrifos in a $10 \mu \mathrm{M}$ solution. Similar luminescence titrations in case of non-aromatic organophosphate pesticides, namely malathion and acephate, did not show any change in the emission intensity (ESI, Fig. S11, S12). The turn-on effect for triazophos and chlorpyrifos can be ascribed to electron rich aromatic ring of the pesticides that increases electron donating effect. The highlight of present methodology is the detection in the aqueous solution at concentrations as low as 0.6 and 0.7 ppm for triazophos and chlorpyrifos respectively.

The observed turn-on luminescence behaviour can be understood on the basis of acceptor-donor electron transfer mechanism (Fig. 8). Usually the CPs have extended network like structures but they generally possess narrow energy bands because of highly localized electronic states. Therefore, their valence and conduction band can be treated similar to that of molecular orbitals. [40] In case of electron rich aromatic species such as triazophos and chlorpyrifos, LUMO is at higher energy than the conduction band of CP. Hence, when excited electrons are transferred from LUMO of the pesticides to the conduction band of CP, there is enhancement in the luminescence intensity. It has been observed that more is the electron donating capacity of the analyte, more is the luminescence enhancement. Higher luminescence intensity (238\%) in case of triazophos as compared to chlorpyrifos can be attributed to additional triazole ring in case of former which makes its richer in the electrons (Fig. 6). Malathion and acephate show no change in the luminescence behaviour of $\mathrm{CP}$ due to the absence of aromatic ring.

In the case of nitroaromatic analytes, the lowest unoccupied MO (LUMO) is a low-lying $\pi^{*}$ - orbital stabilized by the $\mathrm{NO}_{2}$ group through conjugation and its energy is below the conduction band $(\mathrm{CB})$ of coordination polymer. Upon excitation, electrons are transferred from the $\mathrm{CB}$ of coordination polymer to the LUMO of the analyte, leading to a quenching effect. This mechanism has been well-developed for conjugated polymers. For an aromatic pesticide analyte, the excited electrons from its LUMO, a high-lying $\pi^{*}$ antibonding state with its energy above the $\mathrm{CB}$ of the coordination polymer, are transferred to the $\mathrm{CB}$ of coordination polymer, thereby leading to luminescence enhancement (Fig. 8). It should be pointed out that the descriptions/mechanisms are based on the relative orbital energy levels of the coordination polymer and analyte. We also believe that more thorough studies are required in order to fully understand the origin of the quenching/enhancement effect.

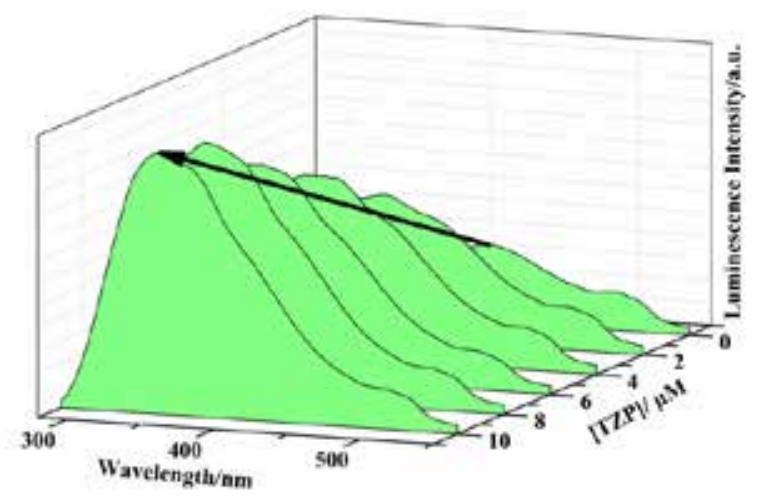

Fig. 7: Emission spectra of 1 dispersed in water upon incremental addition of triazophos solution $\left(\lambda_{\mathrm{ex}}=255 \mathrm{~nm}\right)$.

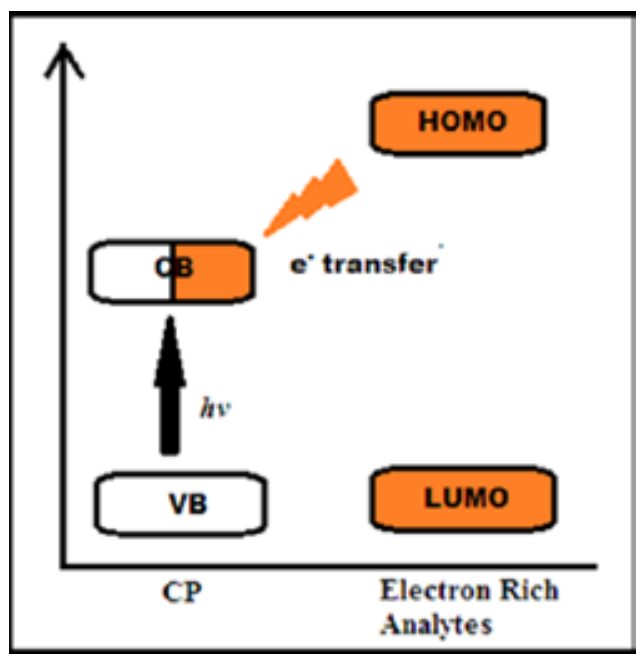

Fig. 8: Schematic representation of photoluminescence turn-on behaviour. 


\section{Experimental Section}

\section{Materials}

Chemicals needed for the synthesis of the $\mathrm{CP}, \mathrm{CoCl}_{2} \cdot 6 \mathrm{H}_{2} \mathrm{O}$ (SDFCL, 98\%), 4, 4'-oxy bis(benzoic acid) (Sigma-Aldrich, 99\%) and $\mathrm{NaOH}$ (SDFCL, 97\%) were used as received. Chemicals used for the luminescence experiments, acetonitrile (Qualigens, 99.5\%), toluene (Merck, 98\%), benzene (99\%), nitrobenzene (99\%), 4-nitrobenzoic acid (97\%), 4-nitrophenol (97\%), and 2,4,6-trinitrophenol (98\%) were used as received from SDFCL whereas 2,6-dintrotoluene (98\%) and 1, 3-dinitrobenzene (98\%) were purchased from Loba Chemie, India and were used without further purification. Pesticides, chlorpyrifos (94\%), malathion (96\%), acephate (95\%) and triazophos (90\%) were procured from Markfed, India. The water used was double distilled and filtered through a Millipore membrane.

\section{Synthesis and initial characterization}

$\mathrm{CP}$ has been synthesized based on the earlier reported procedure. [39] For a typical synthesis, $\mathrm{CoCl}_{2} \cdot 6 \mathrm{H}_{2} \mathrm{O}(0.49 \mathrm{~g}, 2 \mathrm{mM})$ was dissolved in $20 \mathrm{ml}$ of water in a $100 \mathrm{ml}$ beaker. In an another 100 $\mathrm{ml}$ beaker, 4,4'-oxy-bis(benzoic)acid (0.52 g, 2mM) and $\mathrm{NaOH}$ $(0.16 \mathrm{~g}, 4 \mathrm{mM})$ were dissolved in $20 \mathrm{ml}$ of water. Both the solutions were heated at $100^{\circ} \mathrm{C}$ for $20 \mathrm{~min}$. Then the homogeneous solution of 4,4'-oxy-bis(benzoic)acid and $\mathrm{NaOH}$ was poured into the cobalt salt solution and the resulting solution mixture was kept on a hot plate with continuous stirring at $100^{\circ} \mathrm{C}$ for 3 hours. After that it was heated continuously at $80^{\circ} \mathrm{C}$ for 2 days without any stirring. The final product, containing large quantities of dark pink colored (1) homogenous micro crystals, was filtered, washed with deionized water under vacuum, and dried at ambient conditions (Yield $80 \%$ based on Co). Elemental analysis calculated (\%) for 1: C 47.84, H 3.42; found: C 47.65, H 3.33. The products were analyzed by PXRD. The PXRD patterns were consistent with the simulated XRD pattern generated based on the structures determined using single-crystal XRD data of [Co(OBA) $\left.\left(\mathrm{H}_{2} \mathrm{O}\right)_{2}\right]$ (CCDC: 897211) (ESI, Fig. S1).[39]

\section{Instrumentation}

Powder X-ray diffraction (PXRD) studies were done using XPERT PRO Diffractometer $(\mathrm{Cu}-\mathrm{K} \alpha, \lambda=0.15406 \mathrm{~nm}, 45 \mathrm{KV}, 40 \mathrm{~mA}$, step size $=0.013 \AA$ ). The photoluminescence studies were done using Perkin Elmer Spectrofluorometer (LS-45). The photoluminescence properties of CP dispersed in water were investigated at room temperature. The dispersions were prepared by introducing $5 \mathrm{mg}$ of CP into $100 \mathrm{~mL}$ solvent and ultrasonic agitation for 30 minutes. The analytes were added into the dispersion using micro pipette.

\section{Conclusions}

A two-dimensional luminescent cobalt based coordination polymer (CP) has been re-synthesized for the detection of 2,4,6-trinitrophenol through luminescence quenching and for the detection of triazophos and chloropyrifos, aromatic organophosphate pesticides, through luminescence enhancement in the aqueous medium. Both luminescence quenching and enhancement can be explained on the basis of electron transfer mechanisms. The compound, $\mathbf{1}$, demonstrates highly sensitive and selective detection for TNP with lower detection limit of 43 $\mathrm{ppb}$ and for triazophos and chloropyrifos having lower detection limit of 0.6 and $0.7 \mathrm{ppm}$. Other nitroaromatic compounds also show the phenomenon but the percentage quenching is highest in case of TNP. In contrast to this, other common non-aromatic organophosporus pesticides do not show any luminescence turn-on behaviour as shown by aromatic organophosporus pesticides. Present work, for the first time demonstrates the potential of two-in-one use of a CP for the detection of nitro explosive (TNP) and aromatic organophosphorous pesticides in aqueous medium. Thus, two class of compounds having safety and environmental hazard have been detected to very low detection limits for real life applications.

\section{Acknowledgements}

RK thanks UGC for providing Maulana Azad National Fellowship vide letter no. F117.1/201415/MANF-2014-15SIK-CHA-42593/(SAIII/Website). PM thanks DST for DST INSPIRE faculty research grant (IFA12-CH-69) and SERB for Fast track project grant. Authors are thankful to the Director, Thapar University for providing research facilities.

\section{Notes}

$\dagger$ Electronic Supplementary Information (ESI) available: [Details of the experimental data- PXRD pattern of Co-MOF, Stern Volmer plot for TNP and Emission spectra of NB, PNP, 4-NBA, 1,3-DNB, 2,6-DNT, Benzene, Toluene, CPF, ACP and MAL]. This material is available free of charge via Internet at http://

\section{References}

1. Lee, J.; Farha, O. K.; Roberts, J.; Scheidt, K. A.; Nguyen S. T.; Hupp, J. T. Chem. Soc. Rev. 2009, 38, 1450-1459.

2. Collins, D. J.; Zhou, H. C. J. Mater. Chem. 2007, 17, 3154-3160.

3. Li, J. R.; Ma, Y.; McCarthy, M. C.; Sculley, J.; Yu, J.; Jeong, H. K.; Balbuena, P. B.; Zhou, H. C. Coord. Chem. Rev. 2011, 255, 1791-1823.

4. Horcajada, P.; Serre, C.; Maurin, G.; Ramsahye, N. A.; Balas, F.; Vallet-Regi, M.; Sebban, M.; Taulelle, F.; Ferey, G. J. Am. Chem. Soc. 2008, 130, 6774-6780.

5. An, J. Y.; Geib, S. J.; Rosi, N. L. J. Am. Chem. Soc. 2009, 131, 8376-8377.

6. Reineke, T. M.; Eddaoudi, M.; Fehr, M.; Kelley, D.; Yaghi, O. M. J. Am. Chem. Soc. 1999, 121, 1651-1657. 
7. Zhang, Z.; Xiang, S.; Rao, X.; Zheng, Q.; Fronczek, F. R.; Qian, G.; Chen, B. Chem. Commun. 2010, 46, 7205-7207.

8. Harbuzaru, B. V.; Corma, A.; Rey, F.; Jorda, J. L.; Ananias, D.; Carlos L. D.; Rocha, J. Angew. Chem. Int. Ed. 2009, 48, 6476-6479.

9. White, K. A.; Chengelis, D. A.; Gogick, K. A.; Stehman, J.; Rosi, N. L.; Petoud, S. J. Am. Chem. Soc. 2009, 131, 18069-18071.

10. Kreno, L. E.; Leong, K.; Farha, O. K.; Allendorf, M.; Duyne, R. P. V.; Hupp, J. T. Chem. Rev., 2012, 112, 1105-1125.

11. Ma, L.; Evans, O. R.; Foxman, B. M.; Lin, W. Inorg. Chem. 1999, 38, 5837-5840.

12. Bauer, C. A.; Timofeeva, T. V.; Settersten, T. B.; Patterson, B. D.; Liu, V. H.; Simmons, B. A.; Allendorf, M. D. J. Am. Chem. Soc. 2007, 129, 7136-7144.

13. Zhang, L.-Z.; Gu, W.; Li, B.; Liu, X.; Liao, D. Z. Inorg. Chem. 2007, 46, 622-624.

14. Fang, Q.; Zhu, G.; Xue, M.; Sun, J.; Sun, F.; Qiu, S. Inorg. Chem. 2006, 45, 3582-3587.

15. Chelebaeva, E.; Larionova, J.; Guari, Y.; Sá Ferreira, R. A.; Carlos, L. D.; Almeida Paz, F. A.; Trifonov, A.; Guérin, C. Inorg. Chem. 2008, 47, 775-777.

16. Wang, G. H.; Li, Z. G.; Jia, H. Q.; Hu, N. H.; Xu, J. W. Cryst. Eng. Comm. 2009, 11, 292-297.

17. He, G.; Peng, H.; Liu, T.; Wang, M.; Zhang, Y.; Fang, Y. J. Mater. Chem. 2009, 19, 7347-7353.

18. Thomas, S. W.; Joly, G. D.; Swager, T. M. Chem. Rev. 2007, 107, 1339-1386.

19. Nagarkar, S. S.; Desai, A. V.; Ghosh, S. K. Chem. Commun. 2014, 50, 8915-8918.

20. Singha, D. K.; Majee, P.; Mondal, S. K.; Mahata, P. Eur. J. Inorg. Chem. 2015, 2015, 1390-1397.

21. Roy, B.; Bar, A. K.; Gole, B.; Mukherjee, P. S. J. Org. Chem. 2013, 78, 1306-1310.
22. Gallo, M. A.; Lawryk, N. J., in: Handbook of Pesticide Toxicology, Vol. 2, Hayes, W. J., Laws, E. R., Ed., Academic Press, San Diego, 1991, 917-1123.

23. Furton, K. G.; Myers, L. J. Talanta 2001, 54, 487-500.

24. Eiceman, G. A.; Stone, J. A. Anal. Chem. 2004, 76, 390-397.

25. Luggar, R. D.; Farquharson, M. J.; Horrocks, J. A.; Lacey, R. J. X-Ray Spectrom. 1998, 27, 87-94.

26. Hakansson, K.; Coorey, R. V.; Zubarev, R. A.; Talrose, V. L.; Hakansson, P. J. Mass Spectrom. 2000, 35, 337-346.

27. Sylvia, J. M.; Janni, J. A.; Klein, J. D.; Spencer, K. M. Anal. Chem. 2000, 72, 5834-5840.

28. Kandpal, M.; Bandela, A. K.; Hinge, V. K.; Rao, V. R.; Rao, C. P. ACS Appl. Mater. Interfaces 2013, 5, 13448-13456.

29. Moros, J.; Laserna, J. J. Anal. Chem. 2011, 83, 6275-6285.

30. Hallowell, S. F. Talanta 2001, 54, 447-458.

31. Stan, H. J. J. Chromatogr. 2000, 892, 347-377.

32. Chen, P. S.; Huang, S. D. Talanta 2006, 69, 669-675.

33. Leandro, C. C.; Hancock, P.; Fussell, R. J.; Keely, B. J. J. Chromatorgr. A 2006, 1103, 94-101.

34. Zhang, G. L. J. Anhui Agric. Sci. 2003, 31, 663-673.

35. Kazemi, M.; Tahmasbi, A. M.; Valizadeh, R. Agri. Sci. Res. J. 2012, 2, 512-522.

36. Horike, S.; Umeyama, D.; Kitagawa, S. Acc. Chem. Res. 2013, 46, 2376-2384.

37. Kumar, P.; Paul, A. K.; Deep, A. Micropor. \& Mesopor. Mat. 2014, 195, 60-66.

38. Kumar, P.; Paul, A. K.; Deep, A. Anal. Methods 2014, 6, 40954101.

39. Mahata, P.; Drazneiks, C. M.; Roy, P.; Natarajan, S. Cryst. Growth Des. 2013, 13, 155-168.

40. Mahata, P.; Natarajan, S.; Panissod, P.; Drillon, M. J. Am. Chem. Soc. 2009, 131, 10140-10150. 